\title{
A prospective determination of the incidence of perceived inappropriate care in critically ill patients
}

\author{
Rohit K Singal MD², Robert Sibbald MSc ${ }^{2}$, Brenda Morgan RN², Mel Quinlan RN², \\ Neil Parry MD 2,3 , Michael Radford BSc, Claudio M Martin MSc MD 2,3
}

\begin{abstract}
RK Singal, R Sibbald, B Morgan, et al. A prospective determination of the incidence of perceived inappropriate care in critically ill patients. Can Respir J 2014;21(3):165-170.
\end{abstract}

BACKGROUND: Health care providers' perceptions regarding appropriateness in end-of-life treatments have been widely studied. While nurses and physicians believe that rationing and other cost-related practices sometimes occur in the intensive care unit (ICU), they allege that treatment is often excessive.

OBJECTIVE: To prospectively determine the incidence and causes of health care providers' perceptions regarding appropriateness of end-of-life treatments.

METHODS: The present prospective study collected data from patients admitted to the medical-surgical trauma ICU of a 30-bed, Canadian teaching hospital over a three-month period. Daily surveys were completed independently by bedside nurses, charge nurses and attending physician.

RESULTS: In total, 5224 of 6558 expected surveys (representing 294 patients) were analyzed, yielding a response rate of $79.7 \%$. The incidence of perceived inappropriate care in the present study was $6.5 \%$ (19 of 294 patients), with ongoing treatment for $>2$ days after this determination occurring in $1 \%$ (three of 294 patients). However, at least one caregiver perceived inappropriate care at some point in 110 of 294 (37.5\%) patients. In these cases, in which processes to address care were not already underway, respondents believed that important issues resulting in provision of inappropriate treatments included patient-family issues and communication before or in the ICU. Caregivers did not know their patients' wishes 22\% (1129 of 5224) of the time.

CONCLUSIONS: Although ongoing inappropriate care appeared to be a rare occurrence, the issue was a concern to at least one caregiver in onethird of cases. Public awareness for end-of-life issues, adequate communication, and up-to-date knowledge and practice in determining the wishes of critically ill patients are potential target areas to improve end-of-life care and reduce inappropriate care in the ICU. A daily, prospective survey of multidisciplinary caregivers, such as the survey used in the present study, is a viable and valuable means of determining the scope and causes of inappropriate care in the ICU.

Key Words: End of life; Futility; ICU; Inappropriate treatment

$\mathrm{H}$ ealth care providers' perceptions regarding appropriateness in end-of-life treatments have been widely studied. Perceived barriers to optimal end-of-life care include: demands for all possible treatments (1); unrealistic expectations and disagreements about the goals of care (2); and incomplete documentation (3). While nurses and physicians believe that rationing and other cost-related practices sometimes occur in the intensive care unit (ICU), they allege that treatment is often excessive (4). Family demands, lack of team consensus, and cultural or regional variations (5-7) in end-of-life medical management may lead to 'inappropriate, life-prolonging' treatment $(8,9,10)$. The discussion regarding normative judgments of refusing to provide treatment on grounds of futility persists $(10,11)$.

Provision of treatment that is believed to be inappropriate creates a burden over and above resource considerations. Specifically, caregiver distress has been documented with respect to nurses and their experience of moral distress and a negative ethical environment

\section{La détermination prospective de l'incidence d'une perception de soins inadéquats chez des patients gravement malades}

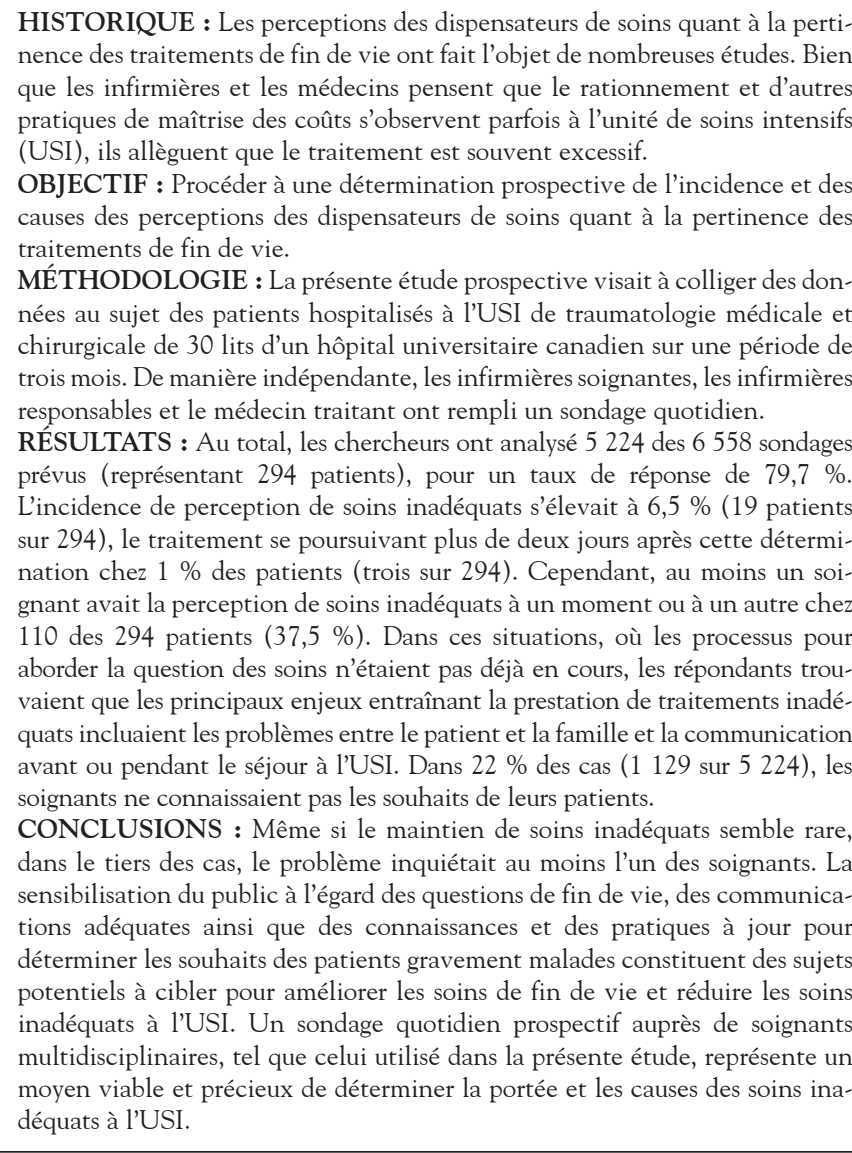
$(12,13)$. This extends to all members of the team, including physicians, particularly in resolving conflict with families and medicolegal concerns (8). In addition, provision of inappropriate life-prolonging treatment has been described as a possible indirect cause of harm to other inpatients (14). Truly inappropriate life-prolonging treatment (ie, treatment that is ineffective in achieving the desired goals) is a disservice to patients who are subjected to ongoing - and likely uncomfortable - conditions with no direct benefit.

Research that aims to better understand the context of 'futility' or perceived inappropriate treatment has focused on many concepts, definitions, causes and potential solutions. However, most of these studies have a significant limitation in that they rely on provider recall of past cases or experiences and, therefore, are subject to several types of bias. Very few studies attempt to collect data on inappropriate lifeprolonging treatment in a prospective manner, making it difficult to generate reliable data on relevant aspects including incidence or scope

${ }^{1}$ Faculty of Medicine, Department of Surgery, University of Manitoba, Winnipeg, Manitoba; ${ }^{2}$ London Health Sciences Centre; ${ }^{3}$ Division of

Critical Care, Schulich School of Medicine and Dentistry, Western University, London, Ontario

Correspondence: Dr Claudio M Martin, 800 Commissioners Road East, London, Ontario N6A 5W9. Telephone 519-685-8090,

fax 519-685-8089, e-mail cmartin1@uwo.ca 
TABLE 1

Survey responses $(n=5224)$

\begin{tabular}{|c|c|c|c|c|}
\hline Question & Yes & Possibly & Unlikely & No \\
\hline 1. Have all treatments besides comfort measures been withdrawn/withheld in this patient? (If 'yes', stop here) & 1.2 & & & 97.8 \\
\hline 2. Do you feel the patient will achieve hospital discharge? & 41.5 & 38.4 & 12.4 & 6.7 \\
\hline 3. Do you feel the patient will achieve a state of relative independence? & 39.0 & 36.1 & 15.3 & 8.6 \\
\hline 4. Do you feel the patient will achieve interactivity with his or her environment? & 58.8 & 28.7 & 7.3 & 4.2 \\
\hline 5. Do you feel the patient wants the level of treatment he or she is receiving? & 74.4 & \multicolumn{2}{|c|}{ I don't know } & 3.0 \\
\hline & & \multicolumn{2}{|c|}{21.6} & \\
\hline 6. Do you feel the most appropriate management at this time is to withdraw life support? & 6.6 & & & 91.1 \\
\hline
\end{tabular}

Data presented as \% of all completed and valid surveys

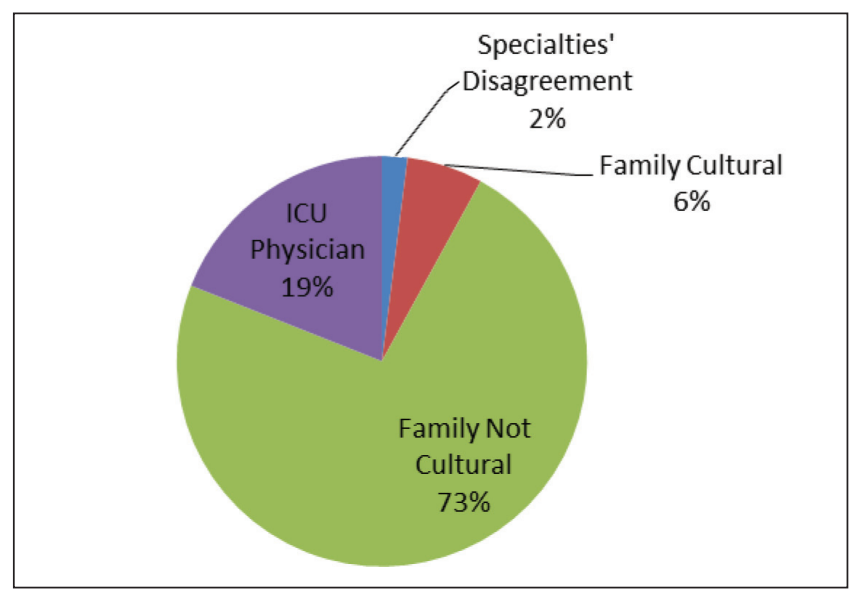

Figure 1) Perceived responsible parties for inappropriate life-prolonging treatment. This figure shows what person or persons were believed to be responsible for ongoing inappropriate life-prolonging treatment when a respondent answered 'no' to question 5 (Do you feel the patient wants the level of treatment he or she is receiving?) or 'yes' to the question 6 (Do you feel the most appropriate management at this time is to withdraw life support?). The respondent was asked if the ongoing provision of this treatment is the result of (pick one): 1. Decision of the family or substitute decision maker FOR CULTURAL REASONS; 2. Decision of the family or substitute decision maker FOR OTHER REASONS; 3. Decision of the intensive care unit (ICU) physician; 4. Disagreement between medical services. 'Cultural' was the perception by the respondent that the family was basing their action on cultural beliefs

of the problem, as well as the 'real-time' perception of why it is occurring. Piers et al (15) prospectively ascertained the perceptions of 1953 nurses and physicians across European and Israeli ICUs in a $24 \mathrm{~h}$ period. They found that $25 \%$ to $33 \%$ of respondents believed that they delivered inappropriate care to at least one of their patients. The definition of inappropriate care used was relatively broad and the study focus was not related to consensus agreements.

The main objectives of the present study were to prospectively investigate how often treatment is perceived to be inappropriate using a stringent definition approximating perceptions that the treatment being provided should not have been ongoing, and to determine how often this opinion was shared by all surveyed members of the team.

\section{METHODS}

All 294 patients admitted to the Critical Care Trauma Centre (CCTC), a 30-bed, tertiary-care, medical-surgical-trauma ICU affiliated with Western University in London (Ontario) between February 19 and May 18,2008 , were enrolled in the present study. This facility is one of two major university ICUs servicing a catchment of 1.5 million residents of southwestern Ontario for all trauma, as well as diverse medical and surgical needs excluding cardiac surgery. A first call intensivist supervised all patient care with support from a second call intensivist, residents in the critical care training program and junior residents from various disciplines. A charge nurse participated in daily, multidisciplinary patient rounds and helped manage patient flow.

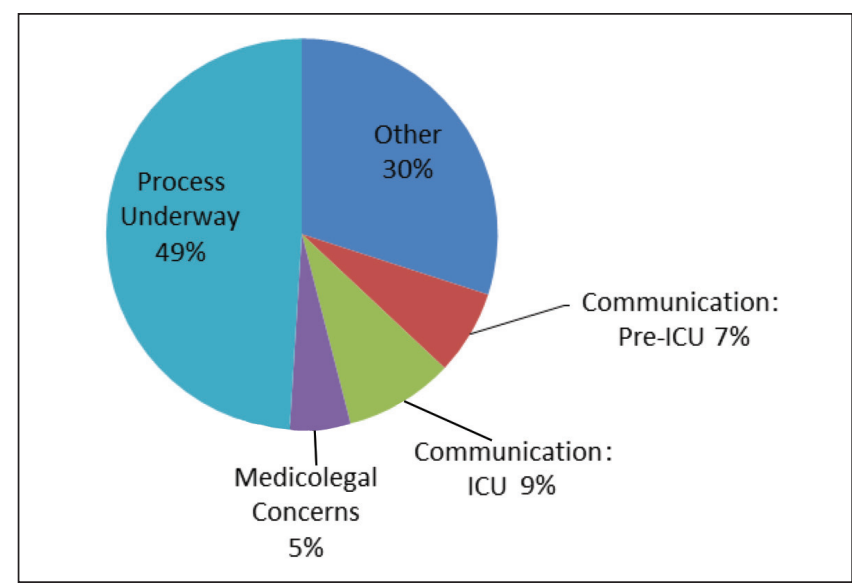

Figure 2) Perceived process issues leading to inappropriate life-prolonging treatment. Similar to Figure 1, this chart shows the process that the respondent perceived to be responsible for ongoing provision of inappropriate lifeprolonging treatment. The respondent was asked if ongoing provision of this treatment is the result of (pick any): 1. Failure of communication before intensive care unit (ICU) admission; 2. Failure of communication on or after ICU admission; 3. Concern regarding medicolegal implications; 4. Process to address care STARTED - ongoing testing and/or decision making is pending; 5. Other, for example, 'continuing for a few days'

A survey (Table 1, Figures 1 and 2) was independently completed every day for each patient by their respective bedside nurse, charge nurse and first-call intensivist. Surveys were distributed each morning by the CCTC administrative clerk, who collected the completed surveys in a sealed envelope at the end of the shift. The survey was a nonvalidated instrument developed by the research team for the present study that relied on common themes generated from the published results of semistructured interviews of multiple treatment providers in Ontario ICUs (4). Items were revised after preliminary presentations for feedback to a multidisciplinary ICU audience, and face validity was established by members of the research team (three intensivists [RS, CM, NP], an ethicist [RS], a clinical nurse specialist $[\mathrm{BM}]$ and a charge nurse $[\mathrm{MQ}])$. Items were constructed to determine nurse and physician perceptions regarding the appropriate level of care, patients' wishes and, in cases for which futility criteria were fulfilled, responsible parties and processes in the provision of ongoing treatment. Conscious of the associations staff may have had with the notion of 'futility', all documentation explicitly focused on the term 'inappropriate treatment' because the term 'futile' is contentious and debatable. The term 'inappropriate treatment', however, recognizes the inherent judgment and subjectivity involved, and aims for a semblance of objectivity. Furthermore, treatment that is not 'futile' may still be inappropriate (eg, in cases for which a patient has indicated that they would not want a particular intervention). For this reason, it was believed that measuring perceptions of appropriateness was actually more valuable than if perceptions of 'futility' had been measured. The tool was tested in the clinical area and refined before the start of the study based on feedback from medical and nursing staff. Respondents 
were informed about the study through e-mail and in-services, but additional definitions or interpretations of the questions and terms in the survey were not provided.

The primary objective of the study was to determine the incidence of perceived inappropriate care. A priori, inappropriate care was defined as agreement on any one day among all three respondents for a particular patient that the patient does not want the treatment he or she is receiving (question 5), or that the most appropriate management at the time is to withdraw life support (question 6). The number of patients fulfilling these criteria were divided by the total number of patients for whom surveys had been completed during the study period to calculate the incidence. Secondary objectives included: characterization of this patient population; quantification of relative causes of perceived inappropriate care provision (answers to questions 7 and 8); incidence of perceived inappropriate care of at least one caregiver; survival outcomes for all patients fulfilling the survey definition of inappropriate care; and how often caregivers believed they knew their patient's wishes. Completed surveys were entered into a spreadsheet (Excel 2007, Microsoft Corporation, USA), and summary and descriptive statistics were prepared.

The present study was reviewed and approved by the Western University Research Ethics Board. Consent from the respondents was inferred by the return of completed surveys.

\section{RESULTS}

During the study period, 294 patients representing 2186 patient days were admitted to the CCTC. In total, 5325 completed surveys, corresponding to an $81.2 \%$ response rate from 6558 potential responses were received. There were 101 (1.9\%) forms that could not be analyzed (incomplete identification of patient, responder, date or data). Thus, 5224 completed surveys (Table 1) were analyzed, yielding an overall response rate of $79.7 \%$. Attending physicians, charge nurses and bedside nurses, respectively, completed $35 \%, 34 \%$ and $31 \%$ of the surveys. The overall mortality rate for the population was $24 \%$.

The primary outcome occurred in 19 of 294 (6.5\%) patients. ICU mortality in these patients was $94.4 \%$ (18 of 19); all 18 deaths occurred secondary to withdrawal or withholding of life support. Characteristics of this patient population relative to the entire cohort for the study period are shown in Table 2. They were older, with higher Acute Physiology and Chronic Health Evaluation II score, with predicted risk of death more often coming from the emergency department or other hospitals, and more often died of respiratory or septic causes. The one patient who survived to hospital discharge was admitted with severe chronic obstructive pulmonary disease exacerbation and died 10 months after the initial admission.

Detailed characteristics of patients perceived to have received inappropriate care are summarized in Table 3. Fifteen of 18 (83\%) deaths occurred within two days of agreement of the three care providers. The other three $(17 \%)$ died six, seven and 10 days after agreement. All of the deaths occurred following withdrawal $(n=16$ [89\%]) or withholding $(\mathrm{n}=2[11 \%])$ of life support.

Of 156 total respondents, 89 (56\%) responded at least once on at least one occasion that withdrawal of life support was appropriate for $110(37.5 \%)$ unique patients (Table 4$)$. The mortality rate in this group was $50 \%$ compared with $24 \%$ in the entire cohort. Excluding patients who fulfilled the primary outcome, the 91 patients having one or two respondents fulfilling survey criteria for inappropriate care on the same day had a mortality rate of $41 \%$. When there was only one team member who believed the level of treatment was inappropriate, it was three times more likely to be the bedside nurse than the physician or charge nurse.

There were 155 of 5224 (3\%) responses representing 62 of 294 patients $(21.1 \%)$ in which it was indicated that the patient did not desire the level of care being provided; the mortality rate in this group was $54 \%$. There was agreement on this latter response among the three team members in only three of these patients. Respondents indicated they did not know the wishes of the patient on 1129 of 5224 (21.6\%) surveys representing 183 of 294 patients $(62.2 \%)$.

\section{TABLE 2}

Characteristics of patients perceived to be receiving inappropriate care

\begin{tabular}{|c|c|c|}
\hline Characteristic & All patients & $\begin{array}{c}\text { Patients with } \\
\text { primary outcome* }\end{array}$ \\
\hline $\mathrm{n}$ & 293 & 19 \\
\hline Age, years, mean \pm SD & $60 \pm 18$ & $72 \pm 10$ \\
\hline Male sex, \% & 57 & 58 \\
\hline \multicolumn{3}{|l|}{ APACHE II } \\
\hline Mean \pm SD & $24.5 \pm 10.0$ & $34.5 \pm 8.1$ \\
\hline Risk (death) & $0.44 \pm 0.30$ & $0.70 \pm 0.23$ \\
\hline $\begin{array}{l}\text { Hospital length of stay, days, } \\
\text { median (range) }\end{array}$ & $9(1-63)$ & $6(2-62)$ \\
\hline $\begin{array}{l}\text { Intensive care unit stay, days, } \\
\text { median (range) }\end{array}$ & $4.1(0.3-103)$ & $5.3(0.7-56)$ \\
\hline Intensive care unit mortality, $\%$ & 24.2 & 94.7 \\
\hline \multicolumn{3}{|l|}{ Source, \% } \\
\hline Emergency & 34 & 53 \\
\hline OR elective & 16 & 6 \\
\hline OR emergency & 10 & 0 \\
\hline Other hospital & 12 & 26 \\
\hline Ward & 28 & 16 \\
\hline \multicolumn{3}{|l|}{ Diagnosis category, $\%$} \\
\hline Cardiovascular & 23 & 16 \\
\hline Respiratory & 27 & 42 \\
\hline Sepsis & 13 & 21 \\
\hline Metabolic & 9 & 6 \\
\hline Gastrointestinal & 11 & 6 \\
\hline Neurological & 3 & 6 \\
\hline Trauma & 9 & 6 \\
\hline Other & 5 & 0 \\
\hline $\begin{array}{l}\text { Decedents' length of stay, } \\
\text { days, mean } \pm \text { SD }\end{array}$ & $8.4 \pm 9.7$ & $1.3 \pm 14.3$ \\
\hline
\end{tabular}

*Primary outcome is agreement on the same day among all three respondents on question 5 or 6. APACHE I| Acute Physiology and Chronic Health Evaluation; OR Operating room

When respondents' surveys fulfilled the criteria for inappropriate care from question 5 or 6 , they were presented with corollary questions to derive insight as to why this was happening. With respect to question 7 (determining which parties were believed to be responsible for provision of ongoing treatment), the overwhelming answer was family for noncultural reasons (73\%), while it was believed to be the decision of the ICU physician in 19\% (Figure 1). Disagreement among treating specialties was believed to be the cause in a minority (2\%) of cases. Question 8 asked respondents to identify process issues that were leading to ongoing treatment. In $49 \%$ of these instances, the respondent believed that the process to address care was already started but ongoing testing or decision making was pending (Figure 2). Communication issues were believed to be responsible in $16 \%$ of cases (7\% before ICU admission, $9 \%$ on or after ICU admission) and medicolegal concerns were cited in $5 \%$ of cases.

\section{DISCUSSION}

In the present study, which proposes an actual incidence of perceived inappropriate care, members of the critical care team were prospectively surveyed daily and independently to determine their perceptions of the appropriateness of care being provided to critically ill patients. Using this methodology, the incidence of inappropriate continuation of life support was $6.5 \%$; however, only three patients in this group continued to receive treatment beyond two days. In general, once treatment was believed to be inappropriate, time was required to complete corollary testing, discuss this with families and to allow them to process the information. Thus, in $50 \%$ of cases in which respondents indicated ongoing treatment was not appropriate, the usual process to 
TABLE 3

Details for patients with agreement among medical doctors, registered nurses and charge nurses regarding withdrawal of life support

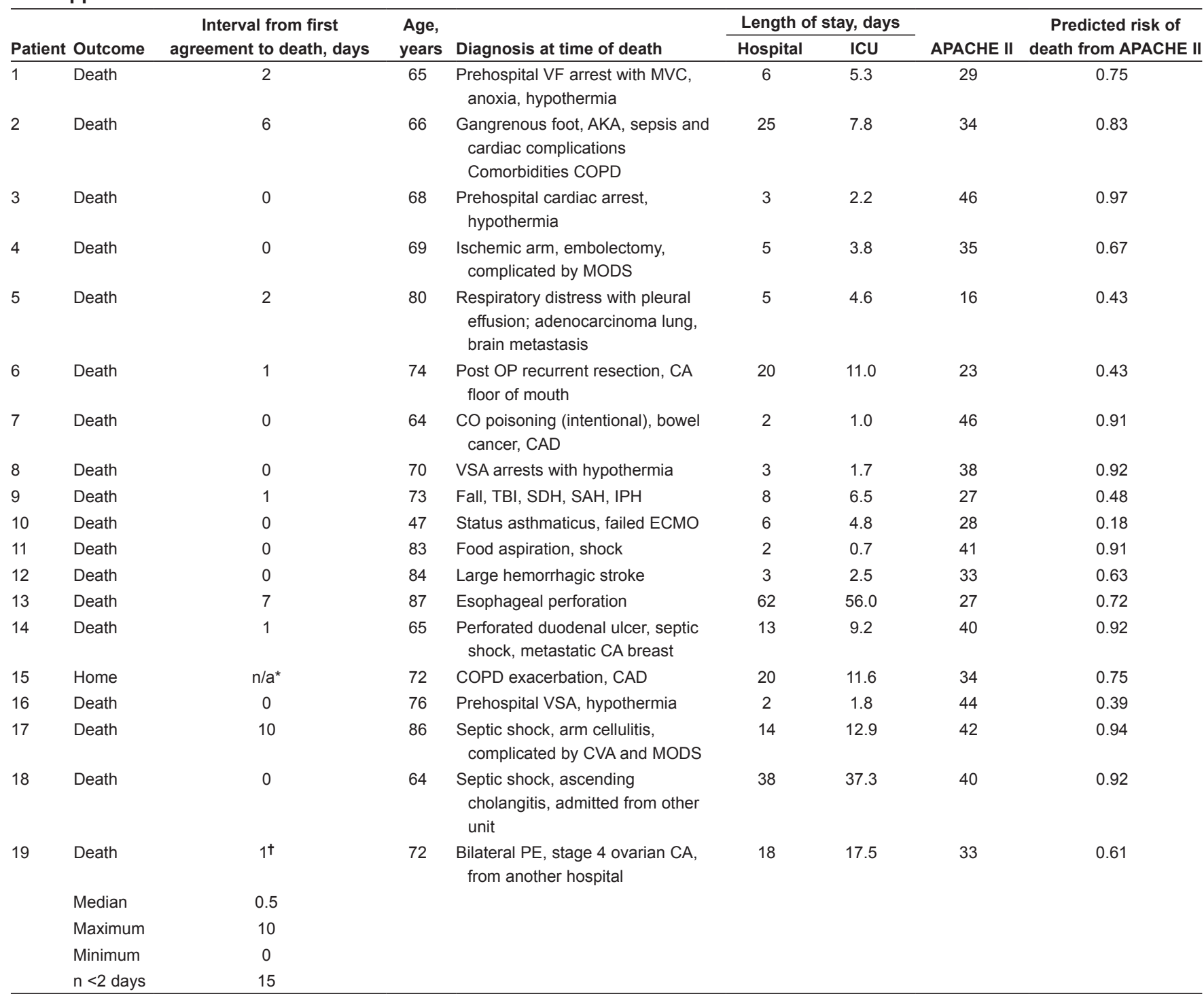

${ }^{*}$ Eight days in intensive care unit (ICU) after agreement, died eight months post ICU discharge; ${ }^{\dagger}$ Consensus on question 5 occurred on day before withdrawal of life support (WLS). AKA Above knee amputation; APACHE II Acute Physiology and Chronic Health Evaluation; CA Cancer; CAD Coronary artery disease; CO Carbon monoxide; COPD Chronic obstructive pulmonary disease; CVA Cerebrovascular accident; ECMO Extracorporeal membrane oxygenation; ICU Intensive care unit; IPH Idiopathic pulmonary hypertension; n/a Not applicable; MODS Multiple organ dysfunction syndrome; MVC Multiple vehicle crash; OP Operative; PE Pulmonary embolism; SAH Subarachnoid hemorrhage; SDH Subdural hemorrhage; TBI Traumatic brain injury; VF Ventricular fibrillation; VSA Vital signs absent

TABLE 4

Perception that withdrawal of life support is appropriate treatment

\begin{tabular}{lccc}
\hline Consensus & $\begin{array}{r}\text { Patient } \\
\text { days, } \mathbf{n}\end{array}$ & $\begin{array}{c}\text { Patients, } \\
\mathbf{n}(\%)\end{array}$ & $\begin{array}{c}\text { Mortality, } \\
\mathbf{n}(\%)\end{array}$ \\
\hline MD, RN, CN & 29 & $19(6.5)$ & $18(95)$ \\
Agreement between two caregivers & & \\
MD, CN & 13 & $10(3.4)$ & $8(80)$ \\
MD, RN & 14 & $7(2.4)$ & $5(71)$ \\
RN, CN & 14 & $14(4.8)$ & $10(71)$ \\
Individual & & & \\
MD only & 29 & $21(7.1)$ & $13(62)$ \\
CN only & 39 & $30(10.2)$ & $17(57)$ \\
RN only & 120 & $77(26.2)$ & $33(43)$ \\
\hline
\end{tabular}

CN Charge nurse; MD Attending physician; RN Bedside nurse address goals of care were underway. Given that our measure of 'inappropriate' was actually a question about the most responsible plan going forward, and that a process of withdrawal requires some time, only the three patients who received treatment for six, seven and 10 days after fulfilling the study end point actually underwent what may be considered to be 'inappropriate treatment' in the present study. With this in mind, the actual incidence of perceived inappropriate treatment for the present study would be $1 \%$. This suggests that the 'actual' provision of inappropriate treatment was lower than may be expected, given the volume of academic literature on this topic including consensus statements, studies on ethics consultation, prediction models and numerous commentaries (16-20).

In the absence of consensus, there was a surprisingly high proportion of patients $(37 \%)$ for whom at least one member of the team believed that treatment was inappropriate. Presumably, these were rooted in reasonable considerations because the mortality of these patients was approximately double that of the entire population $(50 \%$ 
versus $24 \%$, respectively). Cook et al (21) demonstrated that patient survival was lower in cases in which perceived survivability was believed to be low. This is not interpreted as a reflection of the prognostic value of these perceptions, but is important because it reflects a large potential for internal and team conflict regarding the appropriate direction of care. Bedside nurses were the most likely to perceive inappropriateness in cases for which only one caregiver responded this way, which is consistent with previously published studies demonstrating more pessimism but higher accuracy of nurse predictions of patient outcomes (22).

The most common response to the question regarding perceived 'reason' for providing inappropriate treatment was that patient families were responsible $(73 \%)$. In most cases, the process to address care was believed to be underway, but poor communication was described as an impediment in $16 \%$ of cases. One reason that the family was most often considered to be responsible for continuing inappropriate care may be that the general public is poorly informed about the role of critical care in end of life and, not surprisingly, that issues related to communication have a significant role to play in cases of ongoing inappropriate life-prolonging treatment. Studies examining organized communication strategies in the ICU have, in fact, confirmed quicker end-of-life decision making, which may reduce the incidence of inappropriate treatment (23). Despite significant attention devoted to the legal perspective in the literature (24-26), medicolegal concerns were cited by respondents in only $5 \%$ of cases.

It has been shown previously that information regarding patient wishes is poorly documented in ICUs (3). This is occasionally related to lack of a surrogate in an incapacitated patient (27); however, the latest and best data in this area have clearly shown that not only are patient wishes often not discussed, there are many instances in which medical orders regarding goals of care are discordant with their wishes (28). Our study also identified this as a significant issue: respondents believed they did not know patients' wishes $21.6 \%$ of the time. The perception that three of the 19 patients were receiving inappropriate care was based on the criteria indicating that respondents did not believe the patient wanted the treatment they were receiving, once again highlighting discordance as a concerning issue. This question may have been interpreted inconsistently by participants. Some may have answered based on acceptance of a family member's report of the patient's perceived wishes, while others may have responded from a more pragmatic perspective that one rarely ever knows with absolute certainty unless the patient is able to communicate. Nevertheless, it is a reminder that determining the wishes of a critically ill patient remains poorly performed in the ICU. Adequate communication with families is essential in this process, but the general public's preparedness for the situation may be inadequate. This leaves caregivers in a position in which they do not believe they know their patient's wishes one-fifth of the time.

The present study was the first in Canada to prospectively analyze the issue of inappropriate care in critically ill patients from the perspectives of medical caregivers. A Swiss study by Frick et al (22) asked questions similar to those in our study, but attempted to define futility explicitly on the basis of survival and quality of life. Also, participant responses were visible on patient charts; therefore, surveys could not be completed independently. Similar to our results, nurses were more likely than physicians to advocate for withdrawal of life support, but they did not report on agreement among them on this question. It is not clear why this trend appears again; however, one theoretical explanation may relate to the correlation between time spent at the bedside and caregiver stress. Frost et al (7) performed a systematic review of factors influencing end-of-life decision making during critical illness but did not address appropriateness of care or conflict. Another Canadian study (21) addressed factors associated with withdrawal of life support but not the issues surrounding disagreement or inappropriateness in the level of care.

Strengths of the present study include its prospective design, high response rate, inclusion of all patients during a three-month period and the diverse case mix in the study centre. By collecting data daily, caregiver perceptions were assessed 'real-time' throughout the patient stay, generating the closest possible assessment of the incidence of perceived inappropriate treatment. While this may have introduced a bias toward reaching consensus in the longer-stay patients, we believe this approach reflects the reality of critical illness with confidence around prognosis increasing over time. The requirement for consensus was mandated in the study design as a means of ensuring that the perception was less likely to be biased by narrower perspectives and, hopefully, the most specific reflection of perceived 'futility' (although likely not as sensitive). Obviously, this cannot be tested because there is no common understanding of what is meant by 'futility', even among ICU clinicians. However, consensus of the team was believed to be the appropriate marker because this is a clinically influential feature in identifying cases of inappropriate care.

There were several limitations to the present study. First, we chose to assess clinician perceptions that inherently are shaped by personal and idiosyncratic factors. It is unclear whether certain individuals' personal biases influenced the overall results; however, we are reassured by the fact that the response related to the primary objective came uniquely from more than one-half of the total number of respondents. Second, the present analysis was a single-site study with a limited time frame of three months; therefore, the results may not be generalizable. In addition, the ways in which conflicts were resolved or addressed within the present study were not investigated. Another possible limitation to the present study is the possiblity of the 'Hawthorne effect', whether responses by each person were truly independent, and that answering the survey could have triggered or informed discussions that led to withdrawal. However, the survey results themselves were not shared and consensus was only determined after the study was completed. The survey instrument used was not formally developed using published recommendations (29). However, these guidelines are for surveys examining general attitudes while our survey was short and about specific patients. We did undertake a multidisciplinary preparation process and revision before its use. Nineteen patients were still in the ICU at the conclusion of the survey time frame. Some of these patients may have eventually reached our study end point; the unanimous perception was that the next best step in treatment was to withdraw or that the patients did not want the treatment they were receiving. Finally, information was not directly gathered from the patient and family perspective. It would be useful to know the families' awareness of the relevant issues compared with those of the treatment providers.

\section{CONCLUSION}

Unanimous cases of perceived inappropriate treatment were surprisingly rare and, in most cases, not prolonged. This is not to say that individual perceptions of inappropriate treatment were insignificant. Although the actual incidence of the perceived inappropriate treatment may have been lower than expected, it is a source of great concern to caregivers who are mired in the stress of treating critically ill patients day to day. Respondents believed that families were often responsible for ongoing inappropriate treatment and that they did not know their patients' wishes. Thus, public preparedness for end-of-life issues, in-hospital communication and updated strategies of determining the wishes of critically ill patients (ie, protocols, use of checklists, etc) may be targeted to reduce the incidence of inappropriate treatment and improve end-of-life care. The daily survey methodology used in the present study is useful and would generate more robust data if applied to a multicentre scale for a longer duration with identification of a standardized incidence of perceived inappropriate care.

ACKNOWLEDGEMENTS: The authors are indebted to the staff of the CCTC at London Health Sciences Centre, Victoria Hospital for their dedication to exemplary patient care and for completing these surveys. RKS conceived the study, developed the research design, analyzed and interpreted the data and drafted the manuscript. RS contributed to the 
research design, analysis and interpretation of the data and drafting the manuscript. BM and MQ contributed to the research design, data acquisition, interpretation of the data and revision of the manuscript. NP contributed to the research design, interpretation of the data and revision of the manuscript. MR contributed to the acquisition and analysis of the data and revision of the manuscript. CMM contributed to the research design, data analysis, interpretation of the data and revision of the manuscript. All the authors reviewed and approved the final version for submission.

DISCLOSURES: The authors have no financial disclosures or conflicts of interest to declare.

\section{REFERENCES}

1. Moss AH, Demanelis AR, Murray J, Jack J. Barriers to quality endof-life care in West Virginia ICU units: Physicians' and nurses' prospectives. WV Med J 2005;101:200-4.

2. Nelson JE, Angus DC, Weissfeld LA, et al; Critical Care Peer Workgroup of the Promoting Excellence in End-of-Life Care Project. End-of-life care for the critically ill: A national intensive care unit survey. Crit Care Med 2006;34:2547-53.

3. Ratnapalan M, Cooper AB, Scales DC, Pinto R. Documentation of best interest by intensivists: A retrospective study in an Ontario critical care unit. BMC Med Ethics 2010;11:1.

4. Ward NS, Teno JM, Curtis JR, Rubenfeld GD, Levy MM. Perceptions of cost constraints, resource limitations, and rationing in United States intensive care units: Results of a national survey. Crit Care Med 2008;36:471-6.

5. Frost DW, Cook DJ, Heyland DK, Fowler RA. Patient and healthcare professional factors influencing end-of-life decisionmaking during critical illness: A systematic review. Crit Care Med 2011;39:1174-89.

6. Ferrand E, Robert R, Ingrand P, Lemaire F. [Withholding and withdrawal of life support in intensive-care units in France: A prospective survey]. French LATAREA Group. Lancet 2001;357:9-14.

7. Yazigi A, Riachi M, Dabbar G. Withholding and withdrawal of life-sustaining treatment in a Lebanese intensive care unit: A prospective observational study. Intensive Care Med 2005;31:562-7.

8. Sibbald R, Downar J, Hawryluck L. Perceptions of "futile care" among caregivers in intensive care units. CMAJ 2007;177:1201-8.

9. Palda VA, Bowman KW, McLean RF, Chapman MG. "Futile" care: Do we provide it? Why? A semistructured, Canada-wide survey of intensive care unit doctors and nurses. J Crit Care 2005;20:207-13.

10. Vincent JL. Withdrawing may be preferable to withholding. Crit Care 2005;9:226-9.

11. Bagheri A, Asai A, Ida R. Experts' attitudes towards medical futility: An empirical survey from Japan. BMC Med Ethics 2006;7:E8.
12. Hamric AB, Blackhall LJ. Nurse-physician perspectives on the care of dying patients in intensive care units: Collaboration, moral distress, and ethical climate. Crit Care Med 2007;35:422-9.

13. Carvalho KK, Lunardi VL. Therapeutic futility as an ethical issue: Intensive care unit nurses. Rev Latino-am Enfermagem 2009; 17:308-13

14. Niederman MS, Berger JT. The delivery of futile care is harmful to otherpatients. Crit Care Med 2010;38(10 Suppl):S518-22. P

15. Piers RD, Axoulav E, Ricou B, et al; APPROPRICUS Study Group of the Ethics Section of the ESICM. Perceptions of appropriateness of care among European and Israeli intensive care unit nurses and physicians. JAMA 2011:306:2694-703.

16. Carlet J, Thijs LG, Antonelli M, et al. Challenges in end-of-life care in the ICU. Statement of the 5 th International Consensus Conference in Critical Care: Brussels, Belgium, April 2003. Intensive Care Med 2004;30:770-84.

17. Schneiderman LJ, Gilmer T, Teetzel HD, et al. Effect of ethics consultations on nonbeneficial life-sustaining treatments in the intensive care setting: A randomized controlled trial. JAMA 2003;290:1166-72.

18. Afessa B, Keegan MT, Mohammad Z, Finkielman JD, Peters SG. Identifying potentially ineffective care in the sickest critically ill patients on the third ICU day. Chest 2004;126:1905-9.

19. Wilkinson DJ, Savulescu J. Knowing when to stop: Futility in the ICU. Curr Opin Anaesthesiol 2011;24:160-5.

20. Crippen D. Medical treatment for the terminally ill: The 'risk of unacceptable badness'. Crit Care 2005;9:317-8.

21. Cook D, Rocker G, Marshall J, et al. Withdrawal of mechanical ventilation in anticipation of death in the intensive care unit. N Engl J Med 2003;349:1123-32.

22. Frick S, Uehlinger DE, Zuercher Zenklusen RM. Medical futility: Predicting outcome of intensive care unit patients by nurses and doctors - a prospective comparative study. Crit Care Med 2003;31:456-61.

23. Quenot JP, Rigaud JP, Prin S, et al. Impact of an intensive communication strategy on end-of-life practices in the intensive care unit. Intensive Care Med 2012;38:145-52.

24. Luce JM, White DB. A history of ethics and law in the intensive care unit. Crit Care Clin 2009;25:221-37.

25. Druml C. Informed consent of incapable (ICU) patients in Europe: Existing laws and the EU Directive. Curr Opin Crit Care 2004;10:570-3.

26. Sharma BR. Withholding and withdrawing of life support: A medicolegal dilemma. Am J Forensic Med Pathol 2004;25:150-5.

27. White DB, Curtis JR, Lo B, Luce JM. Decisions to limit lifesustaining treatment for critically ill patients who lack both decisionmaking capacity and surrogate decision-makers. Crit Care Med 2006;34:2053-9.

28. Heyland DK, Barwich D, Pichora D, et al; ACCEPT (Advance Care Planning Evaluation in Elderly Patients) Study Team; Canadian Researchers at the End of Life Network (CARENET). Failure to engage hospitalized elderly patients and their families in advance care planning. JAMA Intern Med 2013;173:778-87.

29. Burns K, Duffet M, Kho M, et al. A guide for the design and conduct of self-administered surveys of clinicians. CMAJ 2008;179:245-52. 


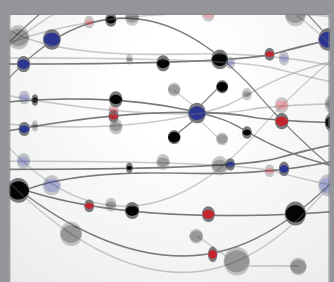

The Scientific World Journal
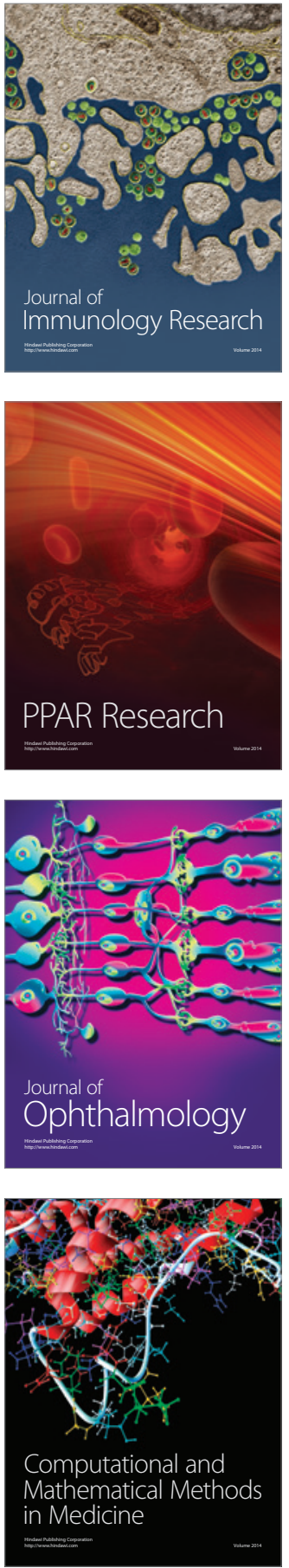

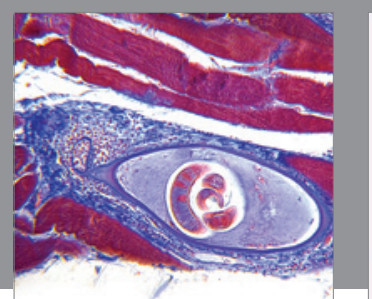

Gastroenterology Research and Practice

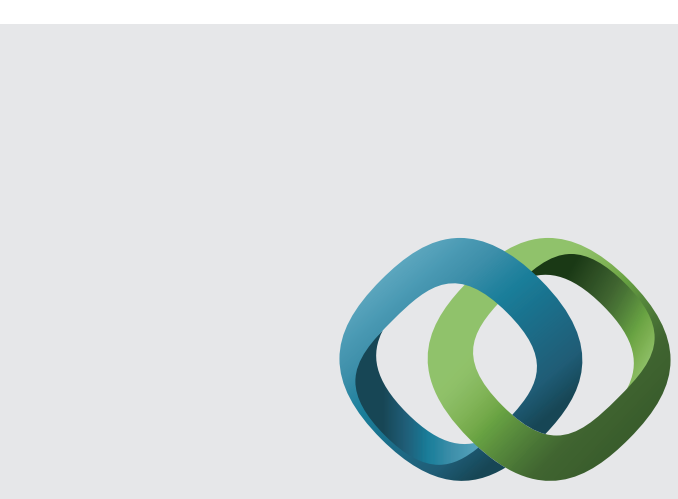

\section{Hindawi}

Submit your manuscripts at

http://www.hindawi.com
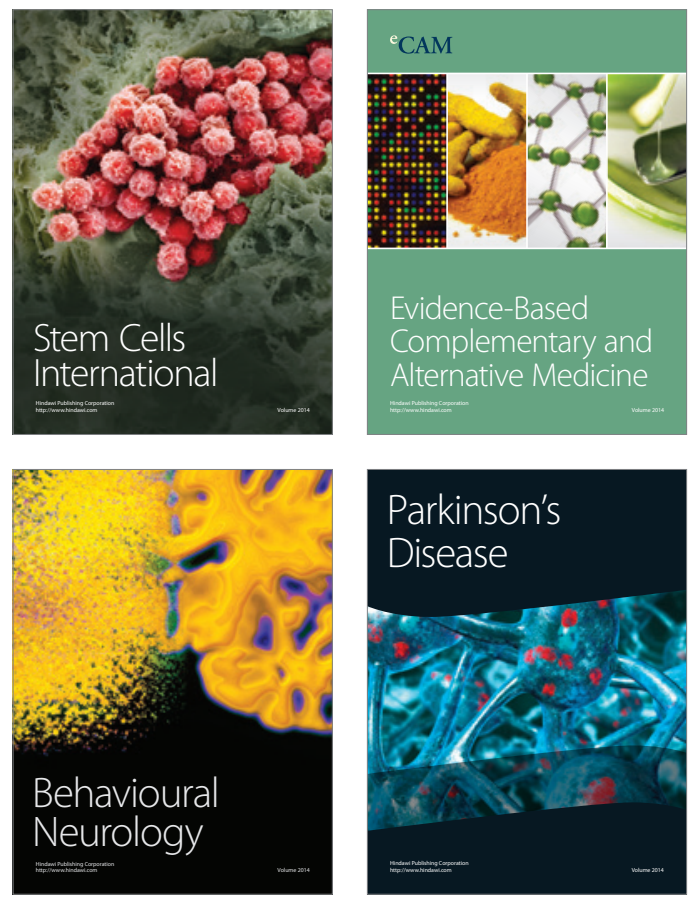
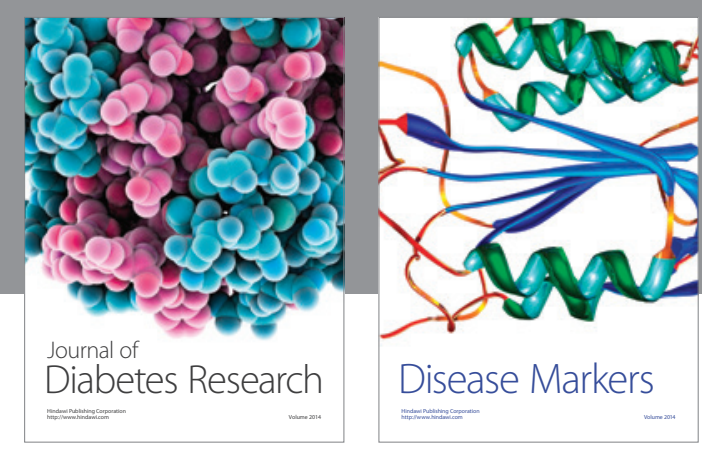

Disease Markers
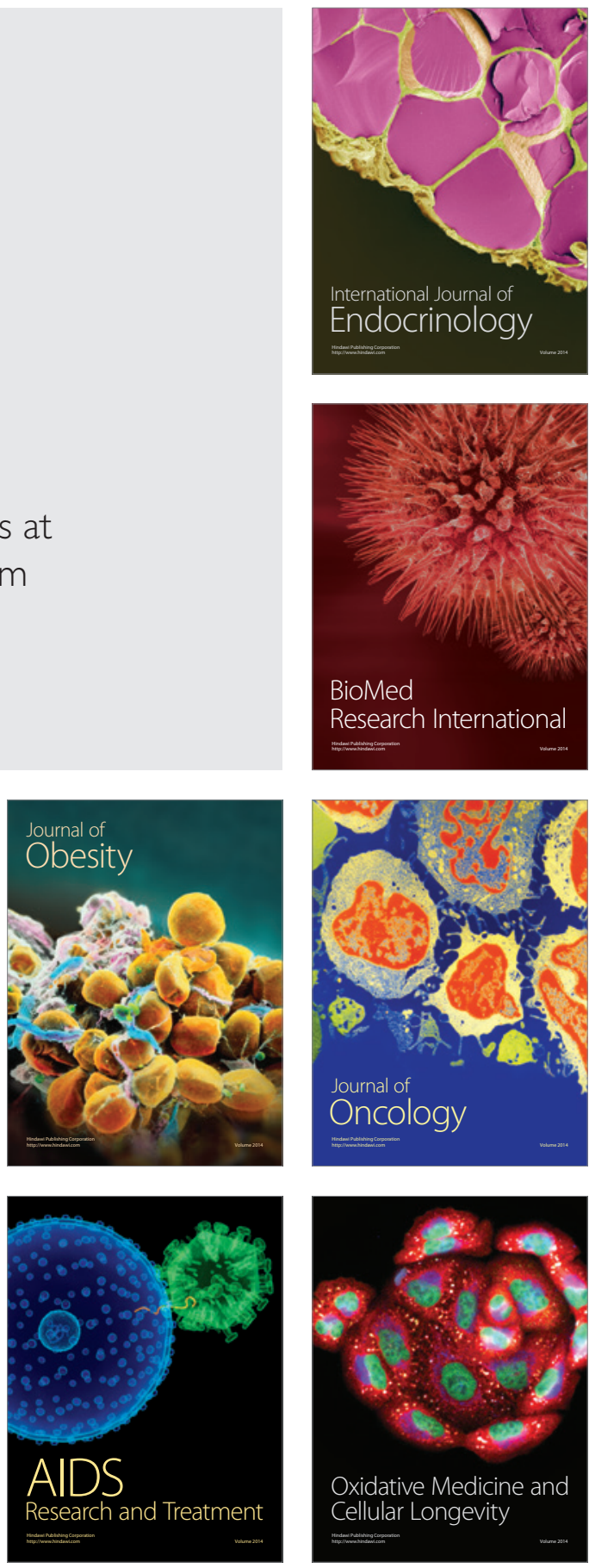